\title{
Interaction of a Short Peptide with G-Quadruplex-Forming Sequences: An SRCD and CD Study
}

\author{
Claudia Honisch ${ }^{1,2}\left(\mathbb{D}\right.$, Eugenio Ragazzi $^{3}\left(\mathbb{D}\right.$, , Rohanah Hussain $^{4}$, John Brazier ${ }^{5}$, Giuliano Siligardi ${ }^{4}$ \\ and Paolo Ruzza $1, *$ (D) \\ 1 Institute of Biomolecular Chemistry of CNR, Via F. Marzolo, 1, 35131 Padova, Italy; \\ claudiahonisch@gmail.com \\ 2 Department of Chemical Sciences, University of Padua, Via F. Marzolo, 1, 35131 Padova, Italy \\ 3 Department of Pharmaceutical and Pharmacological Sciences, University of Padua, Largo Meneghetti, 2, \\ 35131 Padova, Italy; eugenio.ragazzi@unipd.it \\ 4 Diamond Light Source Ltd., Harwell Science and Innovation Campus, Didcot OX11 0DE, UK; \\ rohanah.hussain@diamond.ac.uk (R.H.); giuliano.siligardi@diamond.ac.uk (G.S.) \\ 5 School of Pharmacy, University of Reading, Reading RG6 6DX, UK; j.a.brazier@reading.ac.uk \\ * Correspondence: paolo.ruzza@unipd.it; Tel.: +39-049-827-5282
}

Citation: Honisch, C.; Ragazzi, E.; Hussain, R.; Brazier, J.; Siligardi, G.; Ruzza, P. Interaction of a Short Peptide with G-Quadruplex-Forming Sequences: An SRCD and CD Study. Pharmaceutics 2021, 13, 1104. https://doi.org/10.3390/ pharmaceutics13081104

Academic Editor: Giancarlo Morelli

Received: 10 June 2021

Accepted: 13 July 2021

Published: 21 July 2021

Publisher's Note: MDPI stays neutral with regard to jurisdictional claims in published maps and institutional affiliations.

Copyright: (C) 2021 by the authors. Licensee MDPI, Basel, Switzerland. This article is an open access article distributed under the terms and conditions of the Creative Commons Attribution (CC BY) license (https:/ / creativecommons.org/licenses/by/ $4.0 /)$.

\begin{abstract}
G-quadruplex (G4) forming DNA sequences were recently found to play a crucial role in the regulation of genomic processes such as replication, transcription and translation, also related to serious diseases. Therefore, systems capable of controlling DNA and RNA G-quadruplex structures would be useful for the modulation of various cellular events. In particular, peptides represent good candidates for targeting G-quadruplex structures, since they are easily tailored to enhance their functionality. In this work, we analyzed, by circular dichroism and synchrotron radiation circular dichroism spectroscopies, the interaction of a 25-residue peptide deriving from RHAU helicases (Rhau25) with three G-quadruplex-forming oligonucleotide sequences, in both sodiumand potassium-containing buffers, the most relevant monovalent cations in physiological conditions. The peptide displayed greater affinity for the G4 sequences adopting a parallel structure. However, it showed the ability to also interact with antiparallel or hybrid G-quadruplex structures, inducing a conformation conversion to the parallel structure. The stability of the oligonucleotide structure alone or in presence of the Rhau25 peptide was studied by temperature melting and UV denaturation experiments, and the data showed that the interaction with the peptide stabilized the conformation of oligonucleotide sequences when subjected to stress conditions.
\end{abstract}

Keywords: G-quadruplex DNA; peptide; photo-stability

\section{Introduction}

G-quadruplex (G4) nucleic acid structures, present in guanine-rich nucleic acid sequences, result from the propensity of these sequences to form atypical and thermodynamically stable structures under physiological conditions formed by stacks of Hoogsteenbonded guanine tetrads (Figure 1) [1]. These highly conserved structures, found in both DNA and RNA nucleic acids, have a regulatory role in replication, transcription and recombination [2]. Moreover, G-quadruplex-forming sequences have been also found in viruses [3], bacteria [4] and protozoa [5]. Indeed, studies have shown that G-quadruplex structures play a role in the control of the human immunodeficiency virus-1 [3,6-9], of the Epstein-Barr virus [10], of the human papilloma virus (HPVs) [11], and of Zika virus [12]. Recently, it has been found that G-quadruplex structures are also present in the novel SARS-CoV-2 coronavirus [13]. 


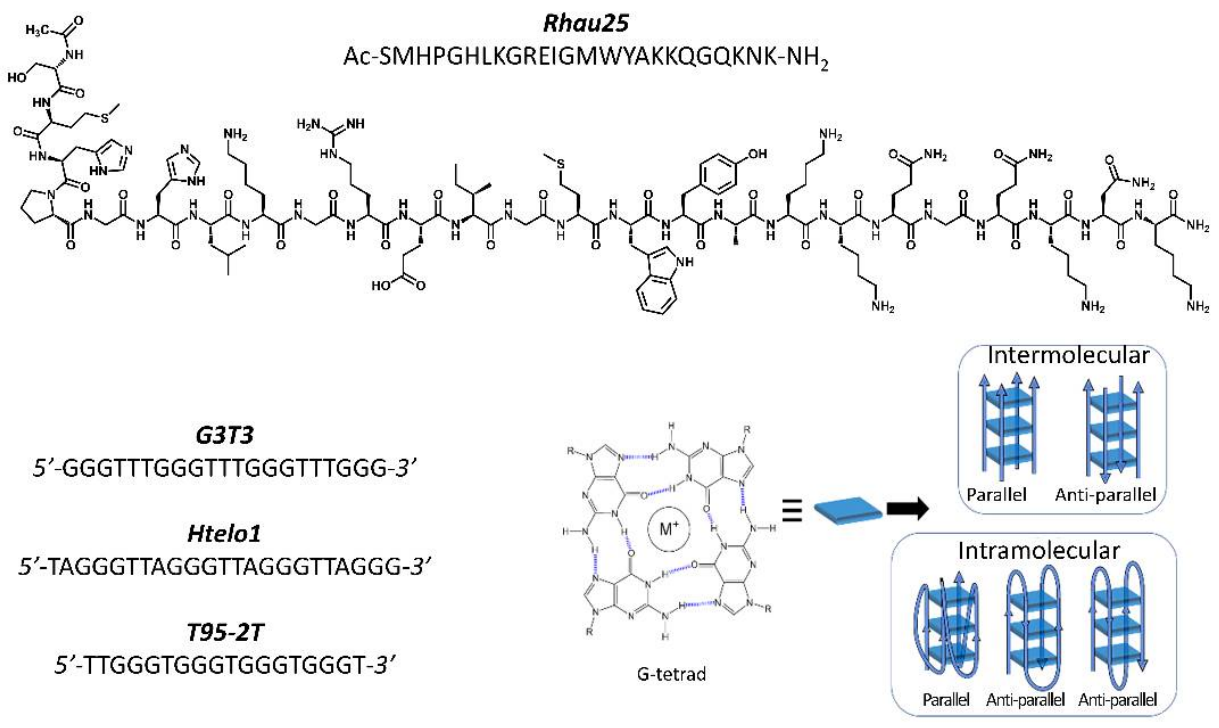

Figure 1. Sequences of the synthetized Rhau25 peptide and G3T3, Htelo1 and T95-2T G-quadruplexforming oligonucleotide sequences with cartoons of the peptide Rhau25, G-tetrad and G4 topologies.

The highest abundance of putative G-quadruplexes sequences is located at telomeres [14], which protect chromosomes from degradation, end-to-end fusions, and are recognized as double-strand break sites [15]. In most telomeric DNAs, guanines and cytosines are distributed asymmetrically between the two DNA strands, with the G-rich strand running $5^{\prime}$ to $3^{\prime}$ from the centromere to the telomere [16].

Systems capable of controlling DNA and RNA G-quadruplex structures would be useful for the modulation of various cellular events and different G-quadruplex-targeting ligands have been described [17,18], including phthalocyanine [19], porphyrin [20], and other derivatives $[21,22]$. From these, peptides represent a class of highly specific ligands with a greater degree of functionality including binding on-off switching, cellular penetration, and the ability to target organelles [23-27]. Among them, the N-terminal domain of the RNA helicase associated with AU-rich element (RHAU), a member of the human DEAH (Asp-Glu-Ala-His) box family of RNA helicases, which includes a specific motif, named RSM, necessary for G-quadruplex recognition and interaction (aa 54-66) [28], has recently raised the interest of several authors [29-32].

With the aim to develop a peptide that selectively interacts with secondary G4 structures we synthesized a peptide, named Rhau 25 (Figure 1), containing the sequence 52-75 of the RHAU protein. The binding of this peptide to G-quadruplex-forming sequences as well as the structure of oligonucleotide sequences and the stability of peptide/oligonucleotide complexes have been evaluated by circular dichroism (CD) spectroscopy using benchtop CD instruments and Diamond B23 beamline for synchrotron radiation circular dichroism (SRCD). This chiroptical spectroscopy is a useful tool for the characterization of Gquadruplex structures and nucleic acids-peptides interactions. Spectroscopic studies were performed in the presence of either sodium or potassium ions, the physiologically relevant monovalent ions involved in the stabilization of cationic coordination with the oxygen atom of the carbonyl group (O6) of guanine.

Metal ion-G4 interaction studies indicated that the position of these ions could be within the quartet plane or between the planes of the quartet depending on ionic radius. Potassium ion (ionic radius $1.33 \AA$ ) is too large to be coordinated in the plane of G-quartet, whereas $\mathrm{Na}^{+}$(ionic radius $0.95 \AA$ ) is small to be coordinated within the plane of G-quartet. Moreover, these studies indicated that $\mathrm{K}^{+}$stabilizes more efficiently $\mathrm{G} 4$ than sodium ion, and that G4 structures exhibit diverse topologies depending on the monovalent cation added [33]. 
Three G-quadruplex-forming sequences (Figure 1), including the human telomeric sequence Htelo1, the T95-2T sequence, and a synthetic sequence named G3T3, have been selected to carry out interaction studies.

In this work, we showed that the selected peptide displays greater affinity for Gquadruplex sequences adopting a parallel conformation, stabilizing this structure towards stress conditions as heating and UV radiation. Moreover, the interaction of the peptide with the oligonucleotide sequence adopting antiparallel or hybrid structures induced a conformational conversion to a parallel G4-structure in the presence of both examined ions.

\section{Materials and Methods}

Oligonucleotide Preparation. Synthetic guanine-rich oligonucleotides were purchased from Eurogentec (Seraing, Belgium). The deoxyoligonucleotides were dissolved in water and allowed to equilibrate overnight at $4{ }^{\circ} \mathrm{C}$ prior to their use; stock solutions were filtered using $0.45 \mu \mathrm{m}$ Millipore syringe filters, and the concentrations were determined by $\mathrm{UV}$ - visible spectrophotometry at $90{ }^{\circ} \mathrm{C}$ to ensure that any secondary structure was fully denatured. G-quadruplex forming sequences were then diluted to the desired concentration in $10 \mathrm{mM}$ Tris- $\mathrm{HCl}$ buffer, $\mathrm{pH}$ 7.4, in presence of $70 \mathrm{mM}$ potassium or sodium ions without annealing. Calf Thymus DNA (ctDNA) sodium salt was purchased from Sigma Aldrich (Milan, Italy) and used without further purification. ctDNA was dissolved in $10 \mathrm{mM}$ Tris- $\mathrm{HCl}$ buffer, $\mathrm{pH} 7.4$, and stirred overnight to allow complete dissolution. The purity of ctDNA was checked by measuring the ratio of $\mathrm{A}_{260} / \mathrm{A}_{280}=1.82$, and the concentration of ctDNA was determined by the absorption of ctDNA at $260 \mathrm{~nm}\left(\varepsilon_{260}=6600 \mathrm{~L} \mathrm{~mol}^{-1} \mathrm{~cm}^{-1}\right)$.

Peptide synthesis. The solid phase peptide synthesis (SPPS) was achieved with the Fmoc/HBTU chemistry approach [34] and carried out automatically using a Biotage ${ }^{\circledR}$ Syro Wave ${ }^{\mathrm{TM}}$ synthesizer (Biotage AB, Uppsala, Sweeden) controlled by Syro XP peptide software. After acetylation by treatment with acetic anhydride, the peptide was detached from the Rink-amide resin along with removal of the side-chain protecting groups by treatment with TFA in presence of TIS and water as scavengers. The peptide was isolated by addition of ethyl ether and purified by elution on a Dionex Vydac reverse phase C18 $300 \AA, 10 \mu, 22 \times 250 \mathrm{~mm}$ column using a preparative Shimadzu HPLC system (Kyoto, Japan) equipped with LC-8A pumps, SLC-8A controller, an SPD-6A spectrophotometric detector, and an ERC-3562 ERMA degasser. LC-ESI-MS analyses were conducted using an Agilent 1260 Infinity II analytical HPLC system (G7129A vialsampler, G7117C DAD HS, and G7111B Quat. Pump) equipped with a 6130 Quadrupole LC-MS analyzer. The calculated mass was 2951.41 Da.

Circular Dichroism. CD spectra were acquired on a Jasco J-1500 CD spectrometer equipped with a Jasco PTC-423S temperature controller (Jasco International, Tokyo, Japan). Far-UV CD spectra were collected in $0.1 \mathrm{~cm}$ pathlength quartz cuvettes (Hellma Analytics, Southend on See, UK) at $25^{\circ} \mathrm{C}$ in the $198-360 \mathrm{~nm}$ range, at $100 \mathrm{~nm} / \mathrm{min}$ scanning speed, $1 \mathrm{~s}$ response time, $2 \mathrm{~nm}$ bandwidth, $0.5 \mathrm{~nm}$ data pitch. The spectra recorded were the average of 4 scans. Peptide concentration was $0.09 \mathrm{mg} / \mathrm{mL}$ in the $10 \mathrm{mM}$ Tris-HCl buffer; $\mathrm{pH}$ 7.4. G4 titration was conducted, adding aliquots of $2 \mu \mathrm{L}$ Rhau 25 peptide $0.29 \mathrm{mM}$ stock solution up to 2.2 molar equivalents to $200 \mu \mathrm{L}$ of $13.5 \mu \mathrm{M}$ oligonucleotide. Spectra were accordingly corrected for dilution.

Synchrotron Radiation Circular Dichroism. SRCD melting experiments were performed in the $10-90{ }^{\circ} \mathrm{C}$ range with $5{ }^{\circ} \mathrm{C}$ steps and allowing 2 min equilibration time. Melting and UV-denaturation measurements were collected on Module A of beamline B23 of Diamond Light Source Ltd synchrotron facility, Harwell Science and Innovation Campus (Didcot, UK). Spectra were recorded in the 198-360 $\mathrm{nm}$ range in $0.1 \mathrm{~cm}$ pathlength quartz cuvettes (Hellma Analytics). Peptide concentration was $0.09 \mathrm{mg} / \mathrm{mL}$ in $10 \mathrm{mM}$ Tris- $\mathrm{HCl}$ buffer, pH 7.4.

CD and SRCD spectra were plotted and analyzed using OriginPro2018 software (OriginLab Corporation, Northampton, MA, USA). The $K_{d}$ values of peptide/G-quadruplex complexes were determined by fitting the titration curves with the Hill equation (Hill1 
function in OriginPro2018 software). Multivariate analysis of spectra was obtained with JMP Pro software version 15 (SAS Institute Inc., Cary, NC, USA).

\section{Results and Discussion}

\subsection{Peptide Design and Secondary Structure}

The Rhau 25 peptide was synthesized by solid phase peptide synthesis (SPPS) using Fmoc/HBTU chemistry, and then purified by preparative RP-HPLC and characterized by LC-ESI-MS (Figure S1 in Supplementary Materials).

The secondary structure of the peptide was evaluated by CD spectroscopy in $10 \mathrm{mM}$ Tris- $\mathrm{HCl}$ buffer, $\mathrm{pH} 7.4$, in presence of $70 \mathrm{mM}$ either sodium or potassium ions. In these conditions, the far-UV CD spectrum of peptide is characterized by the presence of two negative bands at about 200 and $222 \mathrm{~nm}$ (Figure 2), suggesting the presence of an ensemble of a secondary structure as confirmed by the estimation of the secondary structure content (SSE) by the Jasco software. The addition of trifluoroethanol $(20 \%)$ induced a change in the shape of the CD spectrum (Figure 2) and the resulting spectrum adopted the typical profile of $\alpha$-helix as confirmed by the SSE analysis in agreement with the solution structure determined by NMR method of an analogue peptide corresponding to sequences 1-20 of our peptide [28]. The NMR study showed that the peptide adopted an L-shaped structure, containing an $\alpha$-helix spanning from Gly5 to Ala17, and that this structure was retained when the peptide bound to G-quadruplex sequences [28].

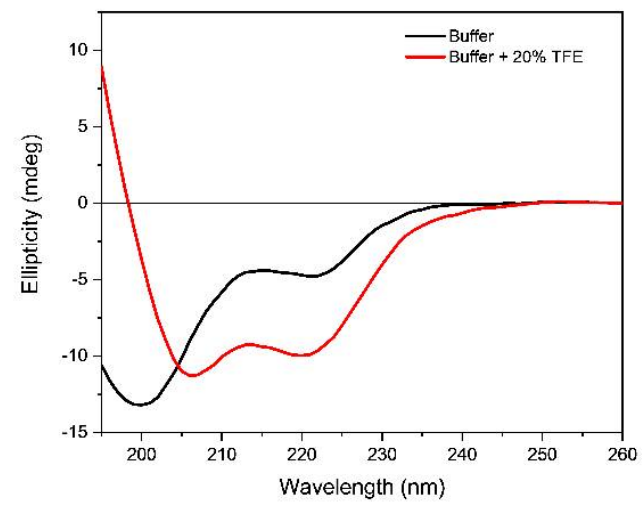

Figure 2. Far-UV CD spectra of Rhau25 peptide $(0.09 \mathrm{mg} / \mathrm{mL}$ or $30.5 \mu \mathrm{M})$ in $10 \mathrm{mM}$ Tris-HCl buffer, $\mathrm{pH} 7.4$, (black line) and in presence of $20 \% v / v$ trifluoroethanol (red line).

In the data obtained by $\mathrm{CD}$ spectroscopy the peptide conformational signature overlaps with those of the G-quadruplex bases and the puckering of the deoxyribose components of the nucleosides in the far-UV spectral region $(185-250 \mathrm{~nm})$. In the near-UV region (250-320 nm), on the other hand, due to the negligible absorption of the Trp and Tyr residues (about 0.021 with peptide concentration of $30 \mu \mathrm{M}$ ), only the conformation of the stacked nucleotide bases are detected that can be successfully used to identify the G-quadruplex topologies.

The determination of the bound conformation of the peptide when bound to the G-quadruplex can only be conducted, at best, qualitatively, as the conformation of the G-quadruplex molecules is induced to different degrees by the binding of the Rhau 25 peptide as demonstrated in Figures 3-5. To do this, the CD spectrum of the complex between the G4 and the peptide at (1:1.8) molar ratio was subtracted from that of the complex with the highest peptide molar ratio of (1:2.2) as illustrated in Figure S4. This is a qualitative assessment as any residual spectral feature in the near-UV region will indicate that the base contributions have not been fully cancelled out, hence making this analysis less accurate. Nevertheless, the results appear to indicate that the conformation of the bound peptide to the G4s for 5 of the 6 complexes are of the more unordered conformation observed for the Rhau25 peptide in Tris- $\mathrm{HCl}$ buffer, while the peptide bound to Htelo1 G-quadruplex sequence appears to bind with a more $\alpha$-helical conformation, though the 
base contributions are quite significant. This is better illustrated by comparing the ratios of the CD intensity at $202 \mathrm{~nm}$ over that at $220 \mathrm{~nm}$ for the calculated spectra of Figure S4.
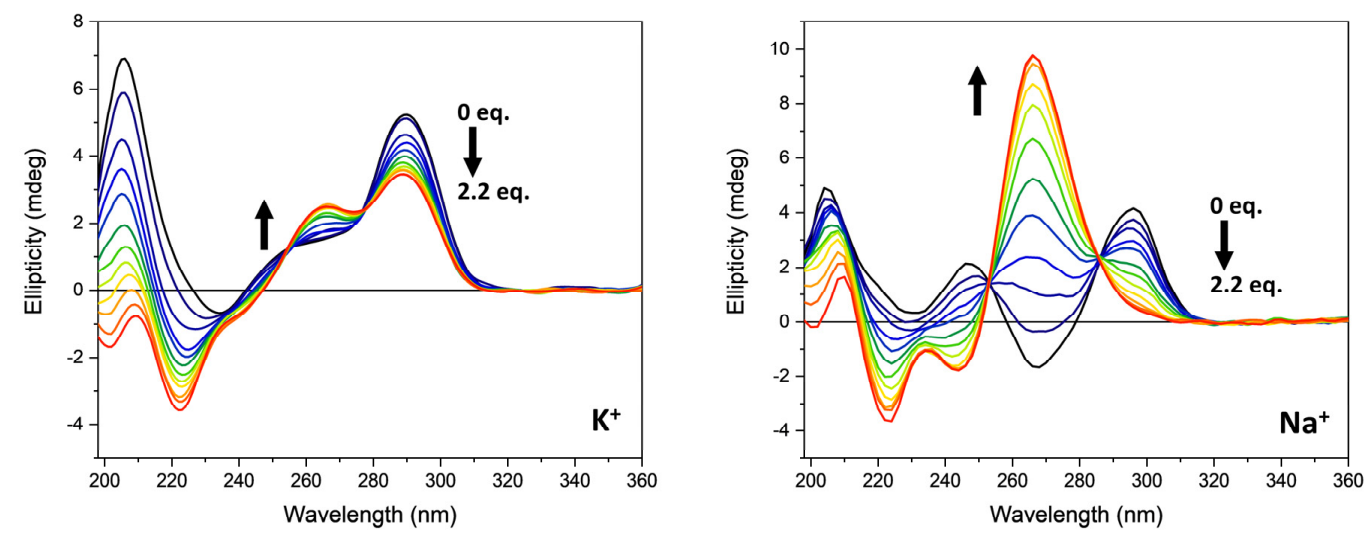

Figure 3. CD spectra of G3T3 $(13.5 \mu \mathrm{M})$ in the absence (black line) and in presence of increasing amounts of Rhau 25 peptide in $10 \mathrm{mM}$ Tris- $\mathrm{HCl}$ buffer, $\mathrm{pH} 7.4,70 \mathrm{mM}$ potassium (left) or sodium ions (right). The arrows represent the direction of the spectral change as the peptide concentration is increased.
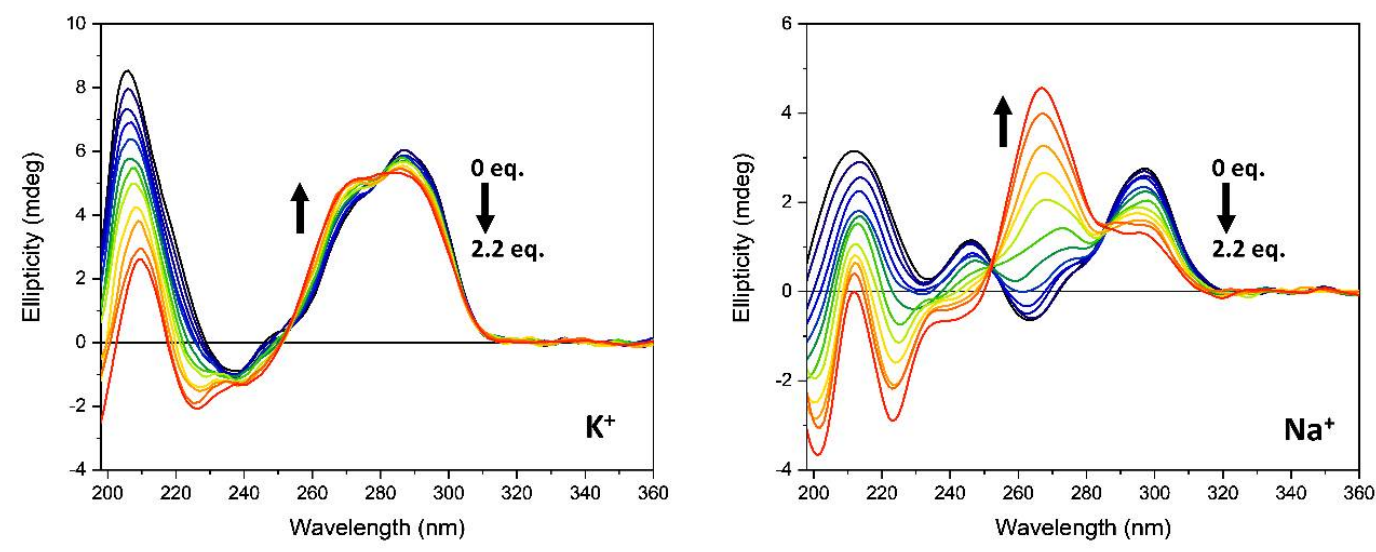

Figure 4. CD spectra of Htelo1 G-quadruplex $(13.5 \mu \mathrm{M})$ in the absence (black line) and in presence of increasing amounts of Rhau 25 peptide in $10 \mathrm{mM}$ Tris- $\mathrm{HCl}$ buffer, $\mathrm{pH} \mathrm{7.4,70} \mathrm{mM}$ potassium (left) or sodium (right) ions. The arrows represent the direction of the signal change as the peptide concentration is increased.
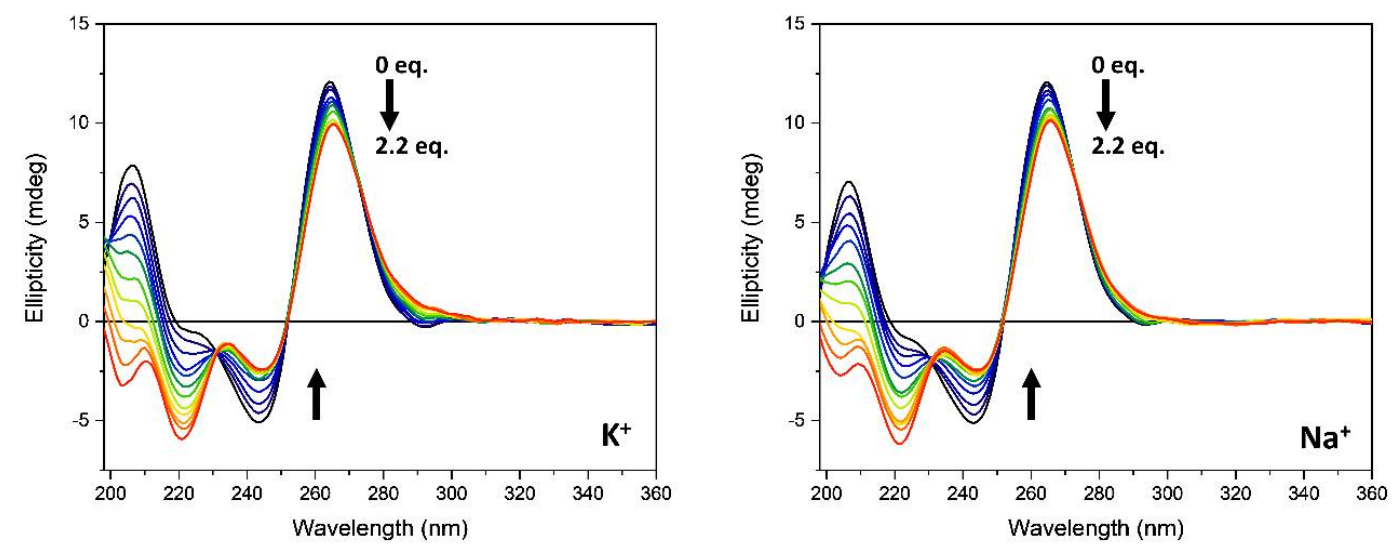

Figure 5. CD spectra of T95-2T G-quadruplex $(13.5 \mu \mathrm{M})$ in the absence (black line) and in the presence of increased amounts of Rhau 25 peptide in $10 \mathrm{mM}$ Tris- $\mathrm{HCl}$ buffer, $\mathrm{pH}$ 7.4, $70 \mathrm{mM}$ potassium (left) or sodium (right) ions. The arrows represent the direction of the spectral change as the peptide concentration is increased. 


\subsection{Peptide G-Quadruplex Interaction}

The ability of the Rhau25 peptide to bind to G3T3, Htelo1, and T95-2T G-quadruplexforming sequences was assessed by CD spectroscopy in the presence of either sodium or potassium ions.

CD spectroscopy, besides allowing for the evaluation of the peptide-G4 interaction, provides useful information on the structure of the oligonucleotide sequence itself, being the 240-300 nm region diagnostic of the G-quadruplex topology [35-38]. Indeed, a parallel G4 structure is characterized by the presence of a positive band at about $264 \mathrm{~nm}$ and a negative band at $245 \mathrm{~nm}$, while antiparallel structure shows a positive band at $295 \mathrm{~nm}$ and a negative band at $260 \mathrm{~nm}[35,37]$. Hybrid or $3+1$ structures show two positive bands at 295 and $260 \mathrm{~nm}$, and a negative band at $245 \mathrm{~nm}$ [38].

As shown in Figure 3, the CD spectrum of G3T3 in presence of $70 \mathrm{mM}$ potassium ions is characterized by a positive band at $290 \mathrm{~nm}$ with a shoulder at about $254 \mathrm{~nm}$, a negative band at $234 \mathrm{~nm}$, and a strong positive band at $205 \mathrm{~nm}$, suggesting the presence of a hybrid or $3+1$ structure. The replacement of potassium with sodium ions induced a drastic change in the CD pattern of G3T3 sequence that is characterized by two positive bands at 296 and $246 \mathrm{~nm}$, respectively, and a negative band at $268 \mathrm{~nm}$. The strong positive band at $205 \mathrm{~nm}$ observed in the presence of potassium ions is still present, but of lower intensity. This spectral feature is typically the CD profile of an antiparallel G4 structure.

The addition of the Rhau25 peptide influenced the CD spectra of the G3T3 sequence in the function of the monovalent cation added to the buffer. In the presence of potassium ions, a decrease in the intensity of the positive band at about $290 \mathrm{~nm}$ accompanied by the appearance of a positive band at about $265 \mathrm{~nm}$ that replaces the shoulder previously described characterized the CD spectrum when the peptide reached a 2.2 peptide/G4 molar ratio (Figure 3, left panel). At wavelengths lower than $240 \mathrm{~nm}$ the dichroic signal contains the contribution of both peptide and G4 sequences and is characterized by the presence of two negative bands at 221 and $200 \mathrm{~nm}$ (Figure 3, left panel). The addition of the Rhau 25 peptide in the presence of sodium ions drastically modified the CD spectrum of G3T3. At the same peptide-G4 molar ratio, an intense peak at $266 \mathrm{~nm}$ accompanied by a negative band at $244 \mathrm{~nm}$ appeared, suggesting a conformational conversion of G3T3 sequence to a parallel quadruplex structure (Figure 3, right). Although the far-UV region (190-240 nm) also contains the CD contribution of the peptide, the G4 CD contribution is the dominating one, showing a negative band at about $222 \mathrm{~nm}$ with a positive band at $210 \mathrm{~nm}$ that is qualitatively similar to that observed in the presence of potassium ions (Figure 3, left). For the G4, the CD contribution in the far-UV region is due to the puckering of the sugar moiety as well as the nucleoside chromophore, whereas the in the near-UV region, it is solely due to the nucleoside electronic transitions. The CD contribution of the peptide, on the other hand, is mainly in the investigated far-UV region below $240 \mathrm{~nm}$ (Figure 2) and negligible in the near-UV region due to the aromatic side-chain of Tyr and Trp residues.

Similarly, the Htelo1 structure was affected by the monovalent cation composition (Figure 4). According to literature data, in the presence of sodium ions, the human telomeric sequence adopts an antiparallel structure [39], while in the presence of potassium ions, the CD spectrum is characterized by a positive band at $287 \mathrm{~nm}$ with a shoulder at 274 and a negative band at $238 \mathrm{~nm}$ (Figure 4, left). The Htelo1 structure in $\mathrm{K}^{+}$solution, on the other hand, had not been as well identified as that in $\mathrm{Na}^{+}$solution and was suggested to contain both antiparallel and parallel arrangements [40-43].

The addition of Rhau25 peptide to the Htelo1 sequence, in the presence of $\mathrm{K}^{+}$, produced minimal modification of the CD spectrum in the G4 diagnostic region (Figure 4, left), while a decreased intensity of the positive band at $206 \mathrm{~nm}$ was observed. On the other hand, in the presence of sodium ions (Figure 4, right), the peak at $290 \mathrm{~nm}$ disappeared in the presence of the Rhau 25 peptide and a conformational conversion to a parallel structure occurred, as revealed by the positive band at $265 \mathrm{~nm}$ which was qualitatively similar to that observed for the G3T3 under the same conditions (Figure 3, right). 
The CD spectrum of T95-2T was unaffected by the nature of the monovalent ions added to the buffer and was characterized by the presence of a strong positive band at about $266 \mathrm{~nm}$ and a negative band at about $245 \mathrm{~nm}$. An additional positive band was observed at $206 \mathrm{~nm}$ in both the explored conditions (Figure 5). The addition of the Rhau25 peptide modified the G-quadruplex T95-2T spectral features in the same manner in the presence of either sodium or potassium ions. In both titrations a decreased intensity of both positive and negative bands at 266 and $245 \mathrm{~nm}$, respectively, were observed indicative of a preserved G-quadruplex parallel structure topology. In the far-UV region below $240 \mathrm{~nm}$, two negative bands at 203 and $221 \mathrm{~nm}$ with similar spectral changes were observed for the titrations in both sodium and potassium ion solutions.

The apparent $K_{d}$ values of peptide/G-quadruplex complexes in either sodium or potassium ions were determined by fitting the titration curves with the Hill equation [44]. The calculated $K_{d}$ values of the investigated G-quadruplex sequences with the Rhau25 peptide in both $\mathrm{KCl}$ and $\mathrm{NaCl}$ conditions, respectively, are summarized in Table 1 . Htelo appears to bind to Rhau 25 peptide with less affinity, demonstrating about half that of G3T3 and T95-2T, which showed similar binding affinities. The cooperativity for all titrations appears to be between 1.5 and 2, indicating that, in all six cases, the binding of the peptide increases the G-quadruplex affinity as more ligand was bound to it, while the stoichiometry appears to be $1: 1$.

Table 1. $K_{d}$ values calculated for each oligonucleotide strand in the presence of Rhau25 peptide.

\begin{tabular}{|c|c|c|}
\hline \multirow[b]{2}{*}{ G4 sequence } & \multicolumn{2}{|c|}{$K_{d}(\mu \mathrm{M})$} \\
\hline & $\mathrm{KCl}$ & $\mathrm{NaCl}$ \\
\hline G3T3 & $12.2 \pm 0.8$ & $14 \pm 0.3$ \\
\hline Htelo1 & $27 \pm 1$ & $30 \pm 8$ \\
\hline T95-2T & $13.5 \pm 0.5$ & $13.9 \pm 1$ \\
\hline
\end{tabular}

In addition, to evaluate the selectivity of Rhau 25 peptide for G4 structures compared to double-stranded DNA molecules, the peptide was titrated with calf thymus DNA (ctDNA). No significant changes in the shape of the peptide spectrum were observed, indicating the lack of interactions with ctDNA, which was successively confirmed by melting and UV-denaturation studies on the Rhau 25 peptide alone or in presence of ctDNA (Figure S2 in Supplementary Materials).

\subsection{Multivariate Statistical Analysis of G-Quadruplex Structure}

Multivariate analysis of CD spectra can offer a satisfactory and reliable evaluation of Gquadruplex topologies such as parallel, antiparallel and so-called "hybrid" [35]. Principal component analysis (PCA) and hierarchical cluster analysis (HCA) were used to obtain an unbiased classification of G-quadruplex structures, independent of simple visual evaluation of the CD spectra with and without the Rhau25 peptide.

To this purpose, a library of 23 CD spectra of various G4 sequences of known highresolution structures from NMR and X-ray of deposited Protein Data Base (pdb) data files was used as the reference base data set and for the multivariate analysis [35].

Figure 6 shows the result of PCA conducted on the CD spectra of reference data together with the 12 experimental conditions herein investigated. Ten out of the 12 investigated data fall in the three main clusters observed in Villar-Guerra et al. [35] indicative of parallel, antiparallel and hybrid G4 topologies (Figure 6). However, Htelo1 with Rhau25 in $\mathrm{Na}^{+}$, and G3T3 with Rhau25 in $\mathrm{K}^{+}$did not fall into any of the three main groups (Figure 6). 


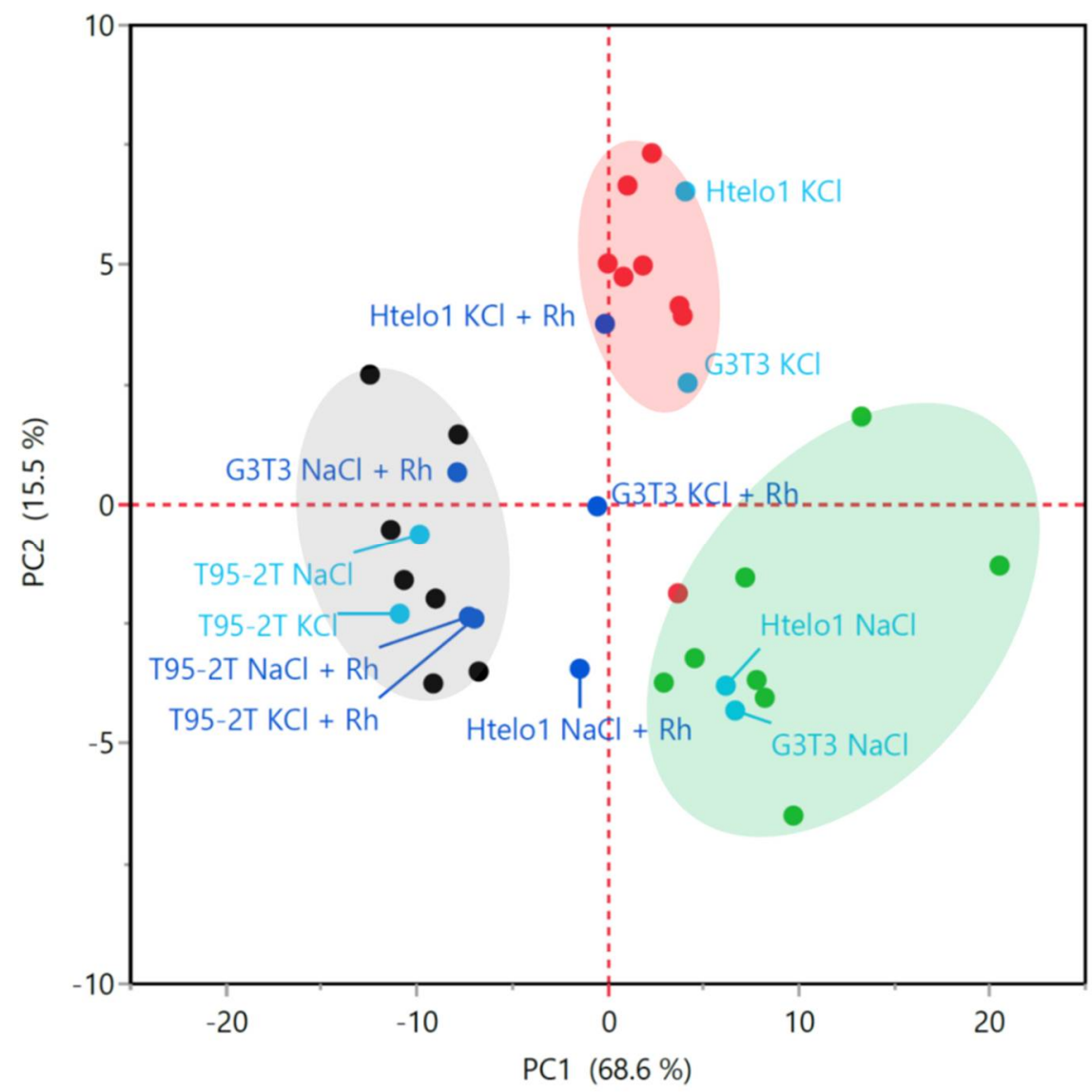

Figure 6. PCA plot of the first and second principal components. In parentheses is the fraction of total variance explained. The blue solid circles represent G3T3, Htelo1, and T95-2T with and without Rhau $25(\mathrm{Rh})$ in $\mathrm{Na}^{+}$and $\mathrm{K}^{+}$respectively (total of 12 samples). The three clusters represent the parallel (grey), antiparallel (green) and hybrid (red) topologies defined by the reference pdb data (black solid circles for grey cluster, green solid circles for green cluster and red solid circles for red cluster [35]). The analysis was carried out using the most distinctive interval of wavelengths $(220-310 \mathrm{~nm})$ of the CD spectra.

Hierarchical cluster analysis confirmed the assignment of the $12 \mathrm{CD}$ spectra to the G4 structure characteristics (Figure 7). For the samples studied here, besides the assignment to parallel and antiparallel classes, the cluster analysis was able to distinguish the "hybrid" class, a further additional group that included the spectra of Htelo1 with Rhau 25 in $\mathrm{Na}^{+}$, and that of G3T3 with peptide in $\mathrm{K}^{+}$isolated from the other 10 spectra with PCA analysis (Figure 6).

From the above results, it is possible to confirm the successful performance of multivariate analysis in estimating the secondary structure of G-quadruplexes, as suggested by [35], and to support the above-described peptide G-quadruplex interaction.

\subsection{Influence of Rhau25 Peptide on G4 Secondary Structure Stability}

Photo-denaturation experiments as well as thermal denaturation experiments [45-47] were carried out to evaluate the folding stability of the G-quadruplex sequences in the presence and absence of the Rhau 25 peptide.

The SRCD spectra were recorded for the annealing process from $10{ }^{\circ} \mathrm{C}$ to $90{ }^{\circ} \mathrm{C}$ every $5{ }^{\circ} \mathrm{C}$. To verify the presence of a two-state mechanism, $\mathrm{F} \leftrightarrow \mathrm{U}$, where $\mathrm{F}$ and $\mathrm{U}$ represent the folded and unfolded states, respectively, in the denaturation of G-quadruplex sequences, melting curves were constructed analyzing the $\mathrm{CD}$ intensity at two different wavelengths. If the two-state assumption is valid, the spectral data at the two wavelengths should be linearly correlated. The SRCD spectra as a function of temperature during the annealing 
process and the corresponding melting curve of Htelo1 in the presence of potassium ions are illustrated in Figure 8 and the calculated $\mathrm{T}_{\mathrm{m}}$ value in Table 2.
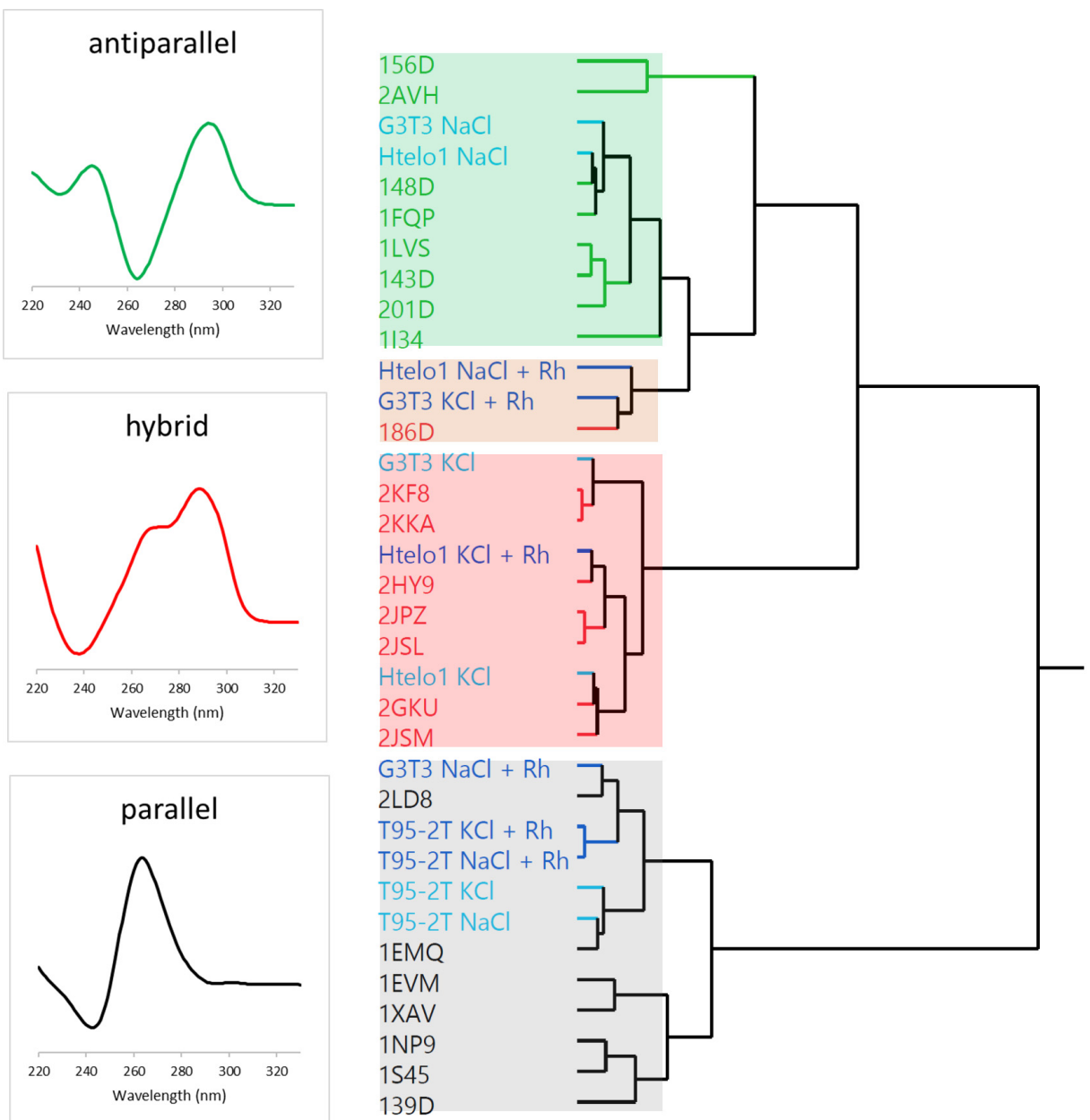

Figure 7. Hierarchical cluster analysis on the CD spectra of experimental samples, evaluated with reference spectra from [35]. The dendrogram on the right indicates three main clusters, comparable to those found with PCA analysis illustrated in Figure 6. For each cluster, a typical associated CD reference spectrum is shown, indicating antiparallel, "hybrid", and parallel G4 topologies, respectively. A further cluster highlighted in amber color includes the spectra of intermediate characteristics. Cluster analysis was obtained according to Ward's minimum variance method using the data of the most distinctive spectra interval of $250-300 \mathrm{~nm}$. 

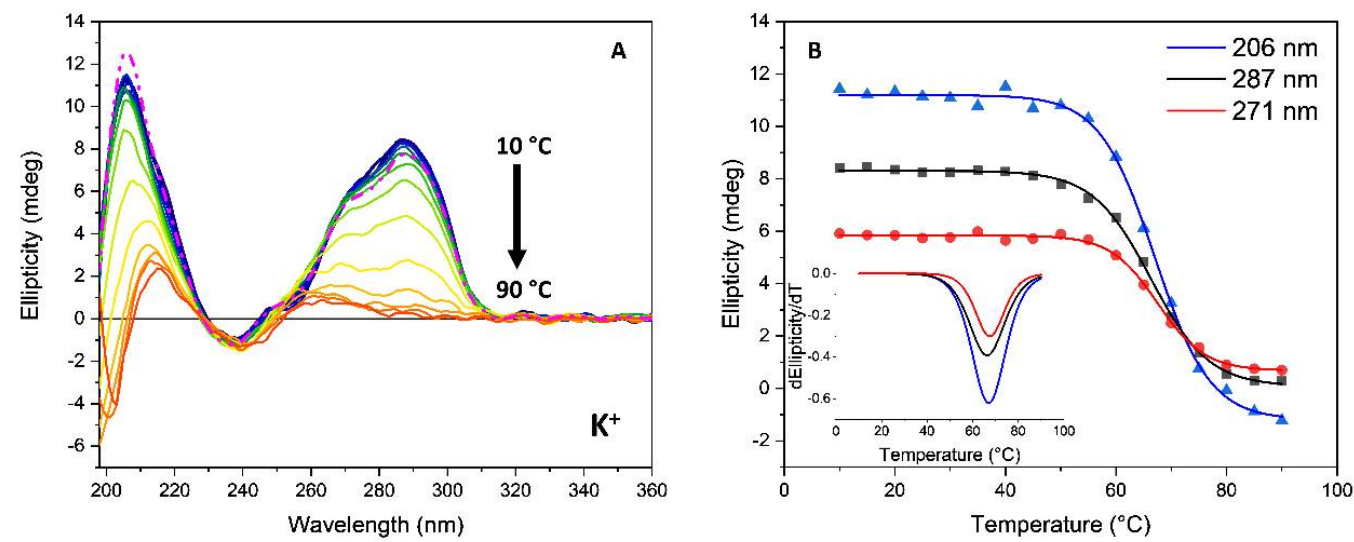

Figure 8. (A) SRCD spectra of Htelo1 $(13.5 \mu \mathrm{M})$ in $10 \mathrm{mM}$ Tris- $\mathrm{HCl}$ buffer, $\mathrm{pH} 7.4$, containing $70 \mathrm{mM}$ potassium ions during the annealing process from $10{ }^{\circ} \mathrm{C}$ to $90{ }^{\circ} \mathrm{C}$ every $5{ }^{\circ} \mathrm{C}$. The dashed line represents the oligonucleotide cooled to $20{ }^{\circ} \mathrm{C}$ after heating to $90{ }^{\circ} \mathrm{C}$. The arrows represent the direction of the spectral change as the temperature increased. (B) SRCD-melting curves at $206 \mathrm{~nm}$ (blue), $271 \mathrm{~nm}$ (black) and $286 \mathrm{~nm}$ (red), respectively. Insert: Comparison of the corresponding first derivative of the SRCD as a function of temperature.

Table 2. Melting temperature values for the G-quadruplex sequences with and without the Rhau 25 peptide.

\begin{tabular}{ccc}
\hline Sample & \multicolumn{2}{c}{ Melting Temperature $\mathbf{T}_{\mathbf{m}}\left({ }^{\circ} \mathbf{C}\right)$} \\
$\mathbf{K C l}$ & $\mathbf{N a C l}$ \\
\hline G3T3 alone & $69 \pm 0.3$ & $51 \pm 0.4$ \\
G3T3 + peptide & n.d. ${ }^{*}$ & $69 \pm 0.3$ \\
Htelo1 alone & $66 \pm 0.3$ & $53 \pm 0.3$ \\
Htelo1 + peptide & n.d. ${ }^{*}$ & $59 \pm 0.4 * \#$ \\
T95-2T alone & $>90$ & $61 \pm 0.2$ \\
T95-2T + peptide & $>90$ & $>90$ \\
\hline n.d. not determinable because of high stability of the structure. ${ }^{*}$ observed conformational conversion. \\
\# determined after 5 h equilibration time.
\end{tabular}

Only the Htelo1 and G3T3 oligomers, in the presence of potassium ions, as well as the G3T3-peptide complex in the presence of sodium ions, showed signs of two-state melting behavior (Figure 8, Figures S5 and S7 in Supplementary Materials) that enabled the calculation of the folded fraction at each temperature. On one side, the sloping of the baselines, which is often observed at low and/or high temperatures, has been fitted with straight lines by other authors to determine the folded fraction [48]. However, on the other side, this behavior could be interpreted as a two-transitions behavior, which shows a less stable conformation with $\mathrm{T}_{\mathrm{m}}$ of about $28^{\circ} \mathrm{C}$ and a more stable conformation with higher $\mathrm{T}_{\mathrm{m}}$ (the latter indicated in Table 2).

In terms of G4 folding, the annealing of G3T3 with 2.2 equivalents of Rhau 25 peptide in $\mathrm{K}^{+}$conducted in the same manner from $10{ }^{\circ} \mathrm{C}$ to $90{ }^{\circ} \mathrm{C}$ every $5{ }^{\circ} \mathrm{C}$ showed an increased content of parallel topology that reached the maximum content at $70^{\circ} \mathrm{C}$ (Figure $9 \mathrm{~B}$ ) as revealed by the emergent positive band at $265 \mathrm{~nm}$ characteristic of the parallel topology (Figure 9A). The repeated thermal melting experiment from $10^{\circ} \mathrm{C}$ to $90^{\circ} \mathrm{C}$ every $10^{\circ} \mathrm{C}$ of the previous annealed G3T3 with Rhau25 peptide (1:2.2) in $\mathrm{K}^{+}$(Figure S9) revealed that the parallel topology was retained, being very stable at high temperatures without denaturing significantly even at $90{ }^{\circ} \mathrm{C}$ (Figure S8). It is important to note that the G3T3 in $\mathrm{K}^{+}$during and after annealing did not adopt the parallel topology (Figure S5, left). Indeed, melting experiment on the G3T3-Rhau25 complex performed on the G4 sample annealed in the presence of peptide shows that Rhau 25 strongly increased the stability of the complex, which did not achieve a fully denatured state at $90^{\circ} \mathrm{C}$ (Figure S8).

The stable parallel topology induced by annealing was also observed for the Htelo1Rhau 25 complex in the presence of potassium ions (Figure 10A). However, this was not the 
case in sodium ions (Figure 10C) where the increased formation of the parallel topology of Htelo1 with 2.2 eq. Rhau 25 in $\mathrm{Na}^{+}$was maximized up to $45^{\circ} \mathrm{C}$, as shown in Figure 10D, suggesting a possible denaturation above this temperature to unstacked single strand DNA. However, the slow conformational transition process may have hindered the accurate determination of the melting temperature of the complex. To verify this hypothesis, the SRCD spectrum of the Htelo1-Rhau25 complex, obtained by addition of 2.2 equivalent of Rhau 25 peptide in a single aliquot to the oligonucleotide rather than titrated with smaller aliquots, was monitored up to $90 \mathrm{~min}$ after the peptide addition (Figure S10). The CD melting experiment on Htelo1 was repeated, allowing $5 \mathrm{~h}$ equilibration time after addition of the peptide, in order to assure the conformational transition would be completed (Figure S11). Therefore, a more accurate melting temperature could be determined (Table 2).

Multivariate statistical analysis of the SRCD spectra of Htelo1-Rhau25 (1:2.2) in either sodium or potassium ions, and G3T3-Rhau25 (1:2.2) solely in potassium ions, cooled to $20^{\circ} \mathrm{C}$ after annealing at $90^{\circ} \mathrm{C}$ showed that these G-quadruplex sequences exhibited a distinct behavior compared to all the other complexes evaluated in this study that are: G3T3Rhau25 (1:2.2) in $\mathrm{Na}^{+}$and T95-2T-Rhau25 in both $\mathrm{K}^{+}$and $\mathrm{Na}^{+}$respectively (Figure S15).
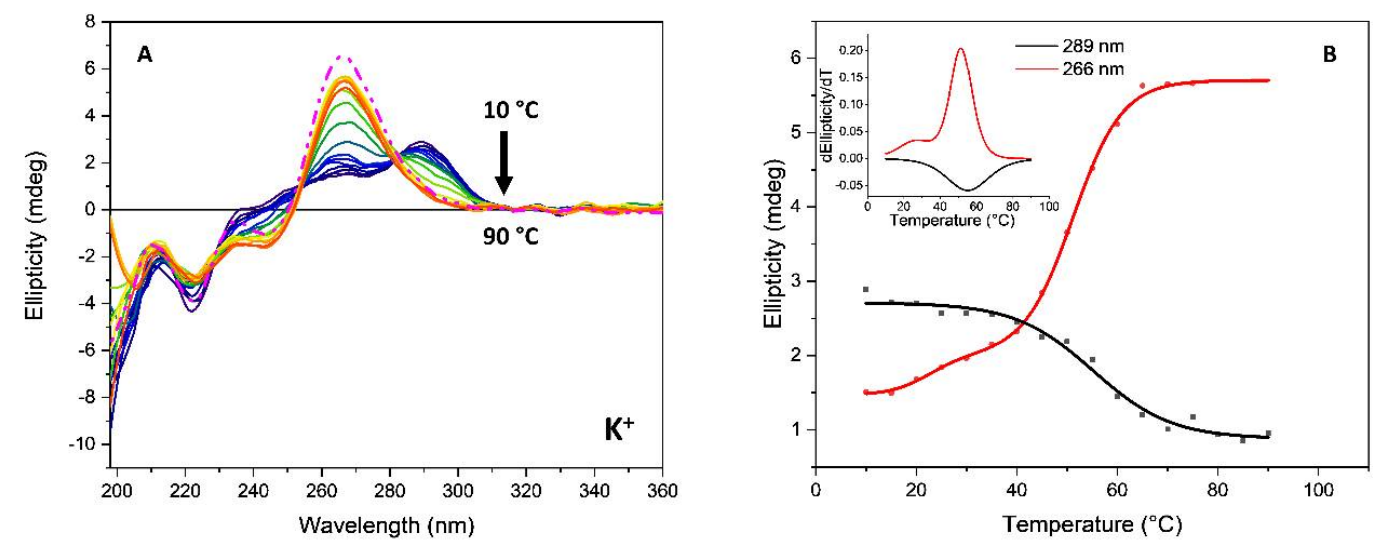

Figure 9. (A) Influence of temperature on the SRCD of G3T3 $(13.5 \mu \mathrm{M})$ with 2.2 eq. of Rhau 25 peptide in $10 \mathrm{mM}$ Tris- $\mathrm{HCl}$ buffer, $\mathrm{pH} 7.4,70 \mathrm{mM}$ potassium ions. The temperature range was from $10{ }^{\circ} \mathrm{C}$ to $90^{\circ} \mathrm{C}$ every $5{ }^{\circ} \mathrm{C}$. The dashed line represents the oligonucleotide cooled to $20^{\circ} \mathrm{C}$ after heating to $90^{\circ} \mathrm{C}$. The arrows represent the direction of the spectral change as the temperature is increased; (B) Plot of SRCD intensity versus temperature at $266 \mathrm{~nm}$ (red) and $289 \mathrm{~nm}$ (black). Insert: Comparison of the corresponding first derivative of the SRCD at $266 \mathrm{~nm}$ and $289 \mathrm{~nm}$. 

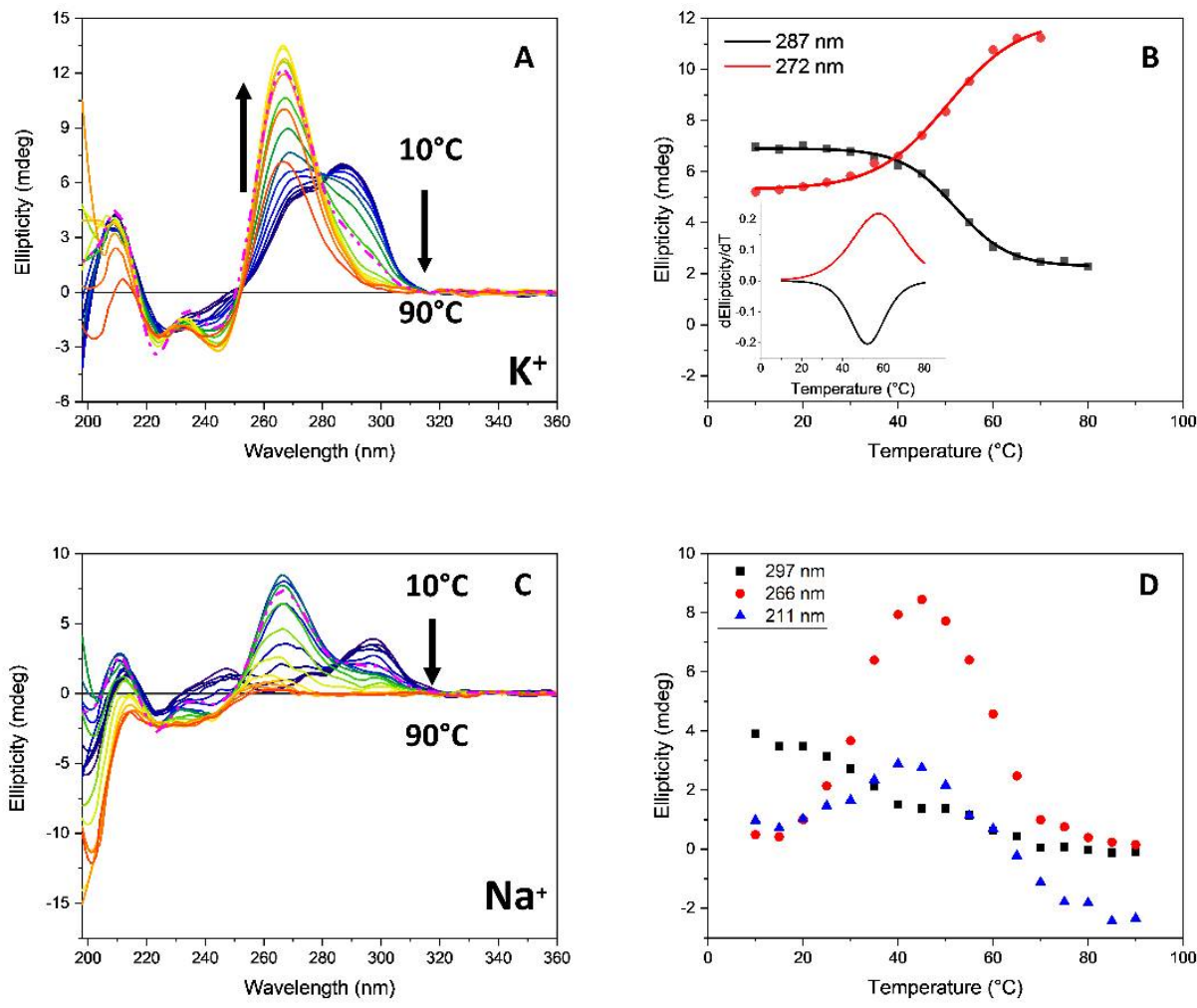

Figure 10. Thermal annealing of SRCD spectra of Htelo1 $(13.5 \mu \mathrm{M})$ with 2.2 eq. of Rhau 25 peptide in $10 \mathrm{mM}$ Tris- $\mathrm{HCl}$ buffer, $\mathrm{pH} 7.4$, containing $70 \mathrm{mM}$ potassium ions $(\mathbf{A})$ or sodium ions $(\mathbf{C})$ from $10{ }^{\circ} \mathrm{C}$ to $90{ }^{\circ} \mathrm{C}$ every $5{ }^{\circ} \mathrm{C}$. The dashed line represents the oligonucleotide cooled to $20^{\circ} \mathrm{C}$ after heating to $90^{\circ} \mathrm{C}$. The arrows represent the direction of the signal change as the temperature is increased. (B) Plots of SRCD intensity versus temperature in $\mathrm{K}^{+}$buffer at $272 \mathrm{~nm}$ (red) and $287 \mathrm{~nm}$ (black) with insert of the corresponding first derivatives. (D) Plots of SRCD versus temperature in $\mathrm{Na}^{+}$buffer at $211 \mathrm{~nm}$ (blue), $266 \mathrm{~nm}$ (red), and $297 \mathrm{~nm}$ (black).

The T95-2T alone in potassium ions (Figure 11A) or when complexed with Rhau25 peptide in the presence of sodium or potassium ions (Figure 5) was remarkably stable in the annealing process, retaining the parallel topology even at $90^{\circ} \mathrm{C}$. For this reason, it was not possible to determine their melting temperature $\mathrm{T}_{\mathrm{m}}$ as the curves were not sigmoidal and the plateau was not reached at higher temperatures (Figure 11). On the contrary, in the presence of sodium ions, the T95-2T alone was able to reach a fully denatured state (Figure 11B,D), allowing the determination of the melting temperature (Table 2). This indicated that the Rhau 25 peptide stabilized the parallel topology of $T 95-2 \mathrm{~T}$ in $\mathrm{Na}^{+}$(Figure 5, right) unlike that in $\mathrm{K}^{+}$where the peptide appeared to be not necessary (Figure 5, left). 

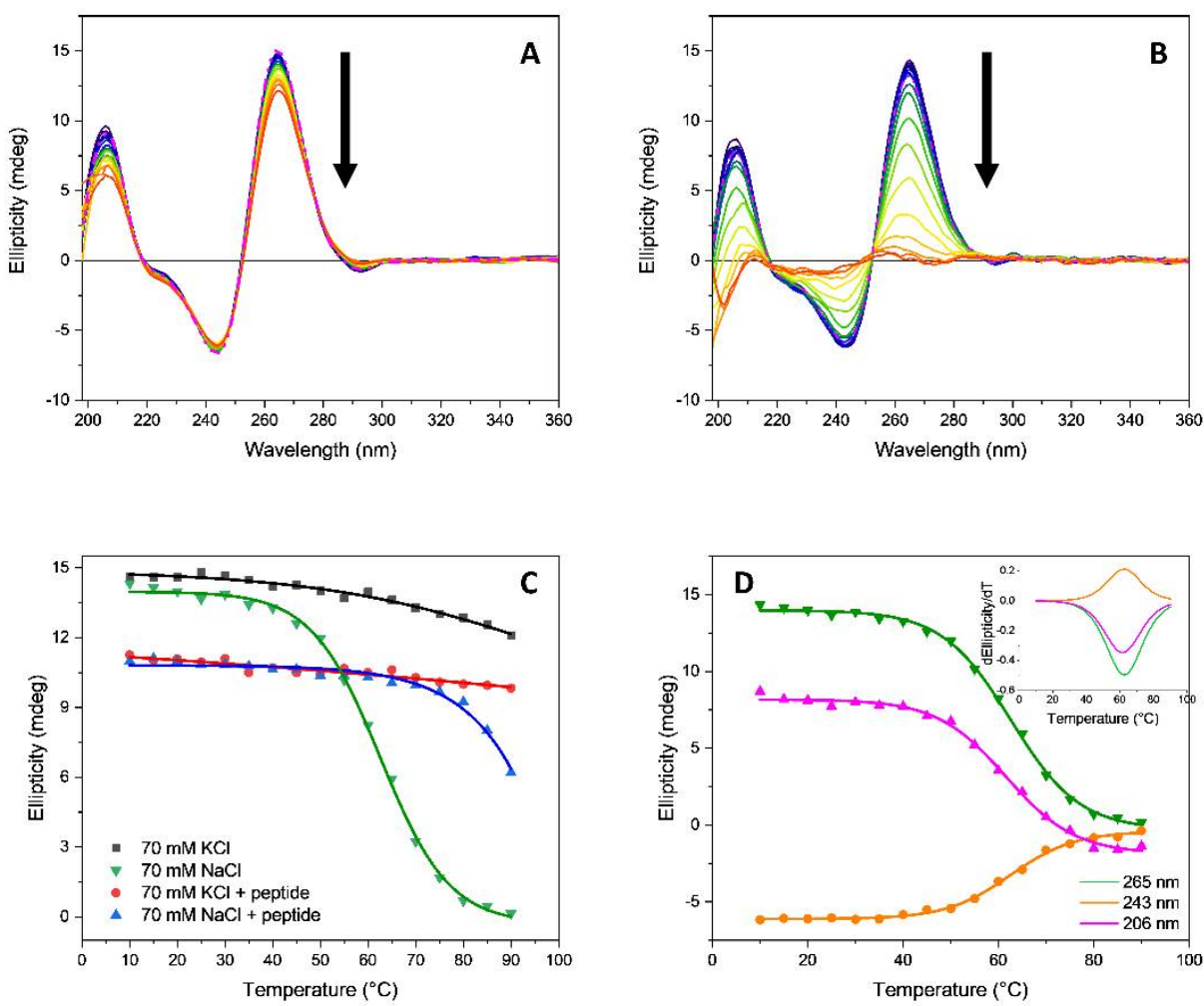

Figure 11. Influence of temperature on the SRCD spectra of T95-2T $(13.5 \mu \mathrm{M})$ in $10 \mathrm{mM}$ Tris-HCl buffer, $\mathrm{pH} 7.4$, containing $70 \mathrm{mM}$ (A) potassium or (B) sodium ions. The temperature varied from 10 to $90{ }^{\circ} \mathrm{C}$. The dashed line represents the oligonucleotide cooled to $20^{\circ} \mathrm{C}$ after heating to $90{ }^{\circ} \mathrm{C}$. The arrows represent the direction of the spectral change as the temperature is increased; (C) SRCD-melting curves in sodium or potassium ions, and in the absence or presence of 2.2 equivalents of Rhau 25 peptide; (D) Melting curves of T95-2T in $10 \mathrm{mM}$ Tris-HCl buffer, $\mathrm{pH} 7.4$, containing $70 \mathrm{mM}$ sodium ions at $206 \mathrm{~nm}$ (magenta), $243 \mathrm{~nm}$ (orange), and $265 \mathrm{~nm}$ (green) with insert for the corresponding first derivatives.

The analysis of the melting curves (Figure 11C) highlights how in $\mathrm{K}^{+}$the parallel topology of T95-2T is more stable and thermally robust than in $\mathrm{Na}^{+}$, even when promoted by the Rhau25 peptide (Figure 11B).

Apart from the G-quadruplex/peptide complexes characterized by a conformational conversion (indicated with * in Table 2), the CD spectra of not annealed and annealed at $20^{\circ} \mathrm{C}$ were almost superimposable, indicating that the G-quadruplexes with or without the peptide were reversible. On the contrary, the conformational conversion induced upon heating was also retained upon cooling, indicating that the new conformation was the preferred one.

Another behavior towards perturbations that is informative and useful to determine is the UV-photo-stability of the G4-sequences in presence or not of the Rhau25 peptide (1:2.2 molar ratio). The CD spectra were recorded as a function of irradiating time with either a UV-C lamp or the synchrotron radiation (Figure 12, Figures S17-S21). Under these conditions, the observed conformational denaturation has been attributed to the action of reactive oxygen species (ROS) generated by the photolysis of water molecules, as recently demonstrated using a positive fluorophore probe [49]. 

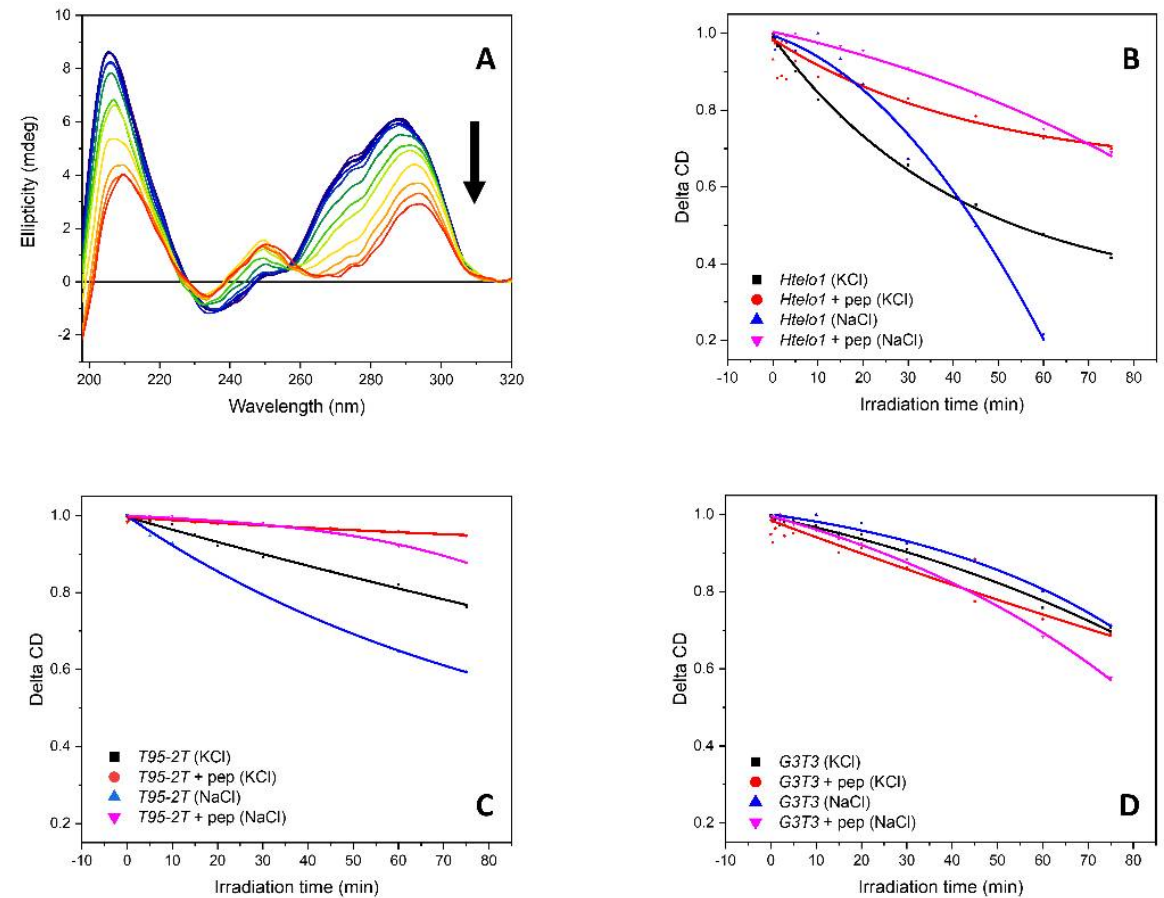

Figure 12. (A) CD spectra G-quadruplex sequence (as example, Htelo1 $13.5 \mu \mathrm{M}$ in $10 \mathrm{mM}$ Tris- $\mathrm{HCl}$ buffer, $\mathrm{pH} 7.4$, in presence of $70 \mathrm{mM}$ potassium ions) as a function of irradiation time with the arrow representing the direction of the spectral change as irradiation time is increased. Normalized rates of denaturation of G-quadruplex-forming sequences with and without the Rhau25 peptide in $70 \mathrm{mM}$ potassium or sodium ions; (B) for Htelo1; (C) for T95-2T; (D) for G3T3.

In terms of relative stability among the three sequences G3T3, Htelo1 and T95-2T investigated under the four conditions of $70 \mathrm{mM} \mathrm{K}^{+}, 70 \mathrm{mM} \mathrm{Na}^{+}$, with and without $2.2 \mathrm{eq}$. of Rhau 25 peptide in $\mathrm{K}^{+}$or $\mathrm{Na}^{+}$, the UV denaturation curves in Figure 12B-D indicated that the sequence T95-2T with 2.2 Rhau 25 peptide in $\mathrm{K}^{+}$(red lines) was the most UV stable followed by both G3T3 and Htelo1. This order was maintained with the peptide in $\mathrm{Na}^{+}$ (blue lines), though these were less stable than those with the peptide in $\mathrm{K}^{+}$(red lines). Without the peptide in $\mathrm{K}^{+}$(black lines), both T95-2T and G3T3 appeared to have similar UV stability followed by the less stable Htelo1. On the other hand, without the peptide in $\mathrm{Na}^{+}$(magenta lines), G3T3 was the most stable followed by T95-2T with Htelo1 the last one.

In terms of relative stability for each G-quadruplex sequence studied under the four conditions of $70 \mathrm{mM} \mathrm{K}^{+}, 70 \mathrm{mM} \mathrm{Na}^{+}$, with and without 2.2 eq. of Rhau 25 peptide in $\mathrm{K}^{+}$or $\mathrm{Na}^{+}$, the UV denaturation curves in Figure 12B-D indicated that the stabilities were more similar for G3T3 than T95-2T than Htelo1 sequences.

In terms of the effect of the Rhau25 peptide on the UV stability of the induced Gquadruplex topology, the G3T3 sequence was less UV stable, suggesting that the addition of the peptide induced a G4 structure more prone to the denaturing effects induced by ROS.

\section{Conclusions}

In this study, circular dichroism spectroscopy was utilized to monitor the structure and interaction with a small peptide, containing the sequence 52-75 of the $\mathrm{N}$-terminal domain of the human RHAU helicases, of three G-quadruplex-forming sequences able to adopt different structure topologies, extending early studies by other authors on the properties of RHAU derived peptides.

We have reported experimental evidence that not only does the Rhau25 peptide specifically recognize parallel G-quadruplex structure, in the T95-2T sequence, with high affinity, but also its interaction with antiparallel or hybrid G3T3 and Htelo1 structures induced a conformational conversion of the G4-strucure to the parallel topology. This 
transition is favored in the presence of sodium ions coordinated within the plane of G4 structure. It is also observed in presence of highly stabilizing potassium ions after annealing the peptide/G4 complexes.

The pharmaceutical relevance of these findings lies in the widespread presence in regions of the genome of G-quadruplex-forming sequences, making these structures a promising drug target not only in the discovery of anticancer but also antiviral drugs, especially against viruses that exhibit latency. Binding to specific G-quadruplex topologies, as the Rhau 25 peptide does, will also be an important aspect of drug design. With numerous G-quadruplexes present in the human genome, binding to one particular structure will be important in targeting transcription of individual genes.

In addition, to directly inhibit the transcriptional mechanism by stabilizing G-quadruplexes, the use of peptide-based drugs can also block the interaction between nucleic acids and specific proteins essential to allow G-quadruplexes to perform their function. Furthermore, the properties of peptides can improve cellular permeation and targeting, increasing the ability to target specific organelles, a feature not always present in small molecules.

Overall, the data presented here confirms the usefulness of multivariate analysis in assigning the G4 secondary structure on the basis of CD spectral profile that can be further used to understand G-quadruplex behavior, inspiring new therapeutic possibilities.

Supplementary Materials: The following are available online at https:/ /www.mdpi.com/article/ 10.3390/pharmaceutics13081104/s1, Figure S1: LC-ESI-MS characterization of the Rhau25 peptide; Figure S2: Interaction of the Rhau25 peptide with ctDNA; Figure S3: CD titration curves of the investigated G4-DNA strands with up to 2.2 eq. Rhau25 peptide; Figure S4: Calculation of the Rhau 25 peptide conformation when interacting with the investigated G4 sequences; Figure S5: CD melting experiment on G3T3 in $\mathrm{KCl}$ buffer; Figure S6: CD melting experiment on $\mathrm{G} 3 \mathrm{T3}$ in $\mathrm{NaCl}$ buffer; Figure S7: CD melting experiment on G3T3 + 2.2 molar equivalents of Rhau 25 in $\mathrm{NaCl}$ buffer; Figure S8: CD melting experiment on G3T3 + 2.2 molar equivalents of Rhau 25 in $\mathrm{KCl}$ buffer after annealing of the G4 sequence in presence of peptide; Figure S9: CD annealing and melting experiments on $\mathrm{G} 3 \mathrm{~T} 3+2.2$ molar equivalents of Rhau 25 in $\mathrm{KCl}$ buffer; Figure S10: Conformational conversion of the Htelo1 quadruplex by the Rhau25 peptide in $\mathrm{NaCl}$ buffer monitored for up to 90 min; Figure S11: CD melting experiment on Htelo1 + 2.2 molar equivalents of Rhau25 in $\mathrm{NaCl}$ buffer after 5 h equilibration time; Figure S12: CD melting experiment on Htelo1 in $\mathrm{NaCl}$ buffer; Figure S13: CD melting experiment on T95-2T +2.2 molar equivalents of Rhau25 in $\mathrm{KCl}$ buffer; Figure S14: CD melting experiment on T95-2T + 2.2 molar equivalents of Rhau 25 in $\mathrm{NaCl}$ buffer; Figure S15: PCA plot identifying the main clusters indicative of G4 conformation, including data recorded at $20^{\circ} \mathrm{C}$ after the heating and cooling experiment for the samples that showed a conformational change; Figure S16: Hierarchical cluster analysis plot identifying the main clusters indicative of G4 conformation including data recorded at $20^{\circ} \mathrm{C}$ after the heating and cooling experiment for the samples that showed a conformational change; Figure S17: UV denaturation experiment of G3T3 alone or in presence of Rhau25 in $\mathrm{KCl}$ buffer; Figure S18: UV denaturation experiment of G3T3 alone or in presence of Rhau25 in NaCl buffer; Figure S19: UV denaturation experiment of Htelo1 alone or in presence of Rhau25 in NaCl buffer; Figure S20: UV denaturation experiment of T95-2T alone or in presence of Rhau25 in KCl buffer; Figure S21: UV denaturation experiment of T95-2T alone or in presence of Rhau 25 in $\mathrm{NaCl}$ buffer.

Author Contributions: Conceptualization, P.R. and J.B.; methodology, G.S. and R.H.; PCA \& cluster analyses, E.R.; formal analysis, P.R.; investigation, C.H.; data curation, C.H.; writing—original draft preparation, P.R.; writing - review and editing, C.H., E.R. and G.S. All authors have read and agreed to the published version of the manuscript. This research project was carried out as part of the doctoral thesis of Honisch Claudia (orcid identifier 0000-0001-9720-6176).

Funding: Costs for publishing in open access covered by the CALIPSOplus project.

Institutional Review Board Statement: Not applicable.

Informed Consent Statement: Not applicable.

Acknowledgments: We thank Rafael del Villar-Guerra, John O. Trent, and Jonathan B. Chaires for kindly providing the $\mathrm{CD}$ data of the $23 \mathrm{G}$-quadruplex sequences for the PCA analysis. Authors are 
grateful for access to beamline B23 (SM21245-1) Diamond Light Source, Ltd., its use being supported by the EU Framework Programme for Research and Innovation HORIZON 2020 under CALIPSOplus (grant agreement 730872).

Conflicts of Interest: R.H. and G.S. are the employees of Diamond Light Source Ltd. The company provided instrument support and data collection in the process of publishing articles. The other authors declare no conflict of interest.

\section{References}

1. Tateishi-Karimata, H.; Sugimoto, N. Chemical biology of non-canonical structures of nucleic acids for therapeutic applications. Chem. Commun. 2020, 56, 2379-2390. [CrossRef] [PubMed]

2. Rhodes, D.; Lipps, H.J. G-quadruplexes and their regulatory roles in biology. Nucleic Acids Res. 2015, 43, 8627-8637. [CrossRef]

3. Ruggiero, E.; Richter, S.N. Viral G-quadruplexes: New frontiers in virus pathogenesis and antiviral therapy. Annu. Rep. Med. Chem. 2020, 54, 101-131.

4. Yadav, P.; Kim, N.; Kumari, M.; Verma, S.; Sharma, T.K.; Yadav, V.; Kumar, A. G-Quadruplex Structures in Bacteria-Biological Relevance and Potential as Antimicrobial Target. J. Bacteriol. 2021, 203, e0057720. [CrossRef] [PubMed]

5. Dumetz, F.; Merrick, C.J. Parasitic Protozoa: Unusual Roles for G-Quadruplexes in Early-Diverging Eukaryotes. Molecules 2019, 24, 1339. [CrossRef]

6. Amrane, S.; Kerkour, A.; Bedrat, A.; Vialet, B.; Andreola, M.-L.; Mergny, J.-L. Topology of a DNA G-Quadruplex Structure Formed in the HIV-1 Promoter: A Potential Target for Anti-HIV Drug Development. J. Am. Chem. Soc. 2014, 136, 5249-5252. [CrossRef] [PubMed]

7. Ruggiero, E.; Tassinari, M.; Perrone, R.; Nadai, M.; Richter, S.N. Stable and Conserved G-Quadruplexes in the Long Terminal Repeat Promoter of Retroviruses. ACS Infect. Dis. 2019, 5, 1150-1159. [CrossRef] [PubMed]

8. Virgilio, A.; Esposito, V.; Tassinari, M.; Nadai, M.; Richter, S.N.; Galeone, A. Novel monomolecular derivatives of the anti-HIV-1 G-quadruplex-forming Hotoda's aptamer containing inversion of polarity sites. Eur. J. Med. Chem. 2020, 208, 112786. [CrossRef]

9. Ruggiero, E.; Richter, S.N. G-quadruplexes and G-quadruplex ligands: Targets and tools in antiviral therapy. Nucleic Acids Res. 2018, 46, 3270-3283. [CrossRef]

10. Murat, P.; Zhong, J.; Lekieffre, L.; Cowieson, N.P.; Clancy, J.L.; Preiss, T.; Balasubramanian, S.; Khanna, R.; Tellam, J. Gquadruplexes regulate Epstein-Barr virus-encoded nuclear antigen 1 mRNA translation. Nat. Chem. Biol. 2014, 10, 358-364. [CrossRef]

11. Marušič, M.; Plavec, J. Towards Understanding of Polymorphism of the G-rich Region of Human Papillomavirus Type 52. Molecules 2019, 24, 1294. [CrossRef] [PubMed]

12. Majee, P.; Pattnaik, A.; Sahoo, B.R.; Shankar, U.; Pattnaik, A.K.; Kumar, A.; Nayak, D. Inhibition of Zika virus replication by G-quadruplex-binding ligands. Mol. Ther.-Nucl. Acids 2021, 23, 691-701. [CrossRef] [PubMed]

13. Ji, D.; Juhas, M.; Tsang, C.M.; Kwok, C.K.; Li, Y.; Zhang, Y. Discovery of G-quadruplex-forming sequences in SARS-CoV-2. Brief. Bioinform. 2021, 22, 1150-1160. [CrossRef] [PubMed]

14. Maizels, N.; Gray, L.T. The G4 genome. PLoS Genet. 2013, 9, e1003468. [CrossRef]

15. Zakian, V.A. Telomeres: The beginnings and ends of eukaryotic chromosomes. Exp. Cell Res. 2012, 318, 1456-1460. [CrossRef] [PubMed]

16. Bochman, M.L.; Paeschke, K.; Zakian, V.A. DNA secondary structures: Stability and function of G-quadruplex structures. Nat. Rev. Genet. 2012, 13, 770-780. [CrossRef] [PubMed]

17. De Cian, A.; Lacroix, L.; Douarre, C.; Temime-Smaali, N.; Trentesaux, C.; Riou, J.F.; Mergny, J.L. Targeting telomeres and telomerase. Biochimie 2008, 90, 131-155. [CrossRef]

18. Hurley, L.H. DNA and its associated processes as targets for cancer therapy. Nat. Rev. Cancer 2002, 2, 188-200. [CrossRef]

19. Yaku, H.; Fujimoto, T.; Murashima, T.; Miyoshi, D.; Sugimoto, N. Phthalocyanines: A new class of G-quadruplex-ligands with many potential applications. Chem. Commun. 2012, 48, 6203-6216. [CrossRef]

20. Cavallari, M.; Garbesi, A.; Di Felice, R. Porphyrin intercalation in G4-DNA quadruplexes by molecular dynamics simulations. J. Phys. Chem. B 2009, 113, 13152-13160. [CrossRef]

21. Sissi, C.; Gatto, B.; Palumbo, M. The evolving world of protein-G-quadruplex recognition: A medicinal chemist's perspective. Biochimie 2011, 93, 1219-1230. [CrossRef]

22. Tucker, W.O.; Shum, K.T.; Tanner, J.A. G-quadruplex DNA aptamers and their ligands: Structure, function and application. Curr. Pharm. Des. 2012, 18, 2014-2026. [CrossRef]

23. Usui, K.; Okada, A. Peptides Targeting G-Quadruplex Structures. In Chemical Biology of Nucleic Acids: Fundamentals and Clinical Applications; Springer: Berlin/Heidelberg, Germany, 2014; pp. 459-475.

24. Liu, K.C.; Röder, K.; Mayer, C.; Adhikari, S.; Wales, D.J.; Balasubramanian, S. Affinity-Selected Bicyclic Peptide G-Quadruplex Ligands Mimic a Protein-like Binding Mechanism. J. Am. Chem. Soc. 2020, 142, 8367-8373. [CrossRef]

25. Biswas, S.; Samui, S.; Das, A.K.; Pasadi, S.; Muniyappa, K.; Naskar, J. Targeting G-quadruplex DNA with synthetic dendritic peptide: Modulation of the proliferation of human cancer cells. RSC Adv. 2020, 10, 26388-26396. [CrossRef]

26. Huang, Z.L.; Dai, J.; Luo, W.H.; Wang, X.G.; Tan, J.H.; Chen, S.B.; Huang, Z.S. Identification of G-Quadruplex-Binding Protein from the Exploration of RGG Motif/G-Quadruplex Interactions. J. Am. Chem. Soc. 2018, 140, 17945-17955. [CrossRef] 
27. Tyagi, S.; Saxena, S.; Kundu, N.; Sharma, T.; Chakraborty, A.; Kaur, S.; Miyoshi, D.; Shankaraswamy, J. Selective recognition of human telomeric G-quadruplex with designed peptide via hydrogen bonding followed by base stacking interactions. RSC Adv. 2019, 9, 40255-40262. [CrossRef]

28. Heddi, B.; Cheong, V.V.; Martadinata, H.; Phan, A.T. Insights into G-quadruplex specific recognition by the DEAH-box helicase RHAU: Solution structure of a peptide-quadruplex complex. PNAS 2015, 112, 9608-9613. [CrossRef] [PubMed]

29. Ariyo, E.O.; Booy, E.P.; Patel, T.R.; Dzananovic, E.; McRae, E.K.; Meier, M.; McEleney, K.; Stetefeld, J.; McKenna, S.A. Biophysical Characterization of G-Quadruplex Recognition in the PITX1 mRNA by the Specificity Domain of the Helicase RHAU. PLoS ONE 2015, 10, e0144510. [CrossRef]

30. Chen, M.C.; Tippana, R.; Demeshkina, N.A.; Murat, P.; Balasubramanian, S.; Myong, S.; Ferré-D'Amaré, A.R. Structural basis of G-quadruplex unfolding by the DEAH/RHA helicase DHX36. Nature 2018, 558, 465-469. [CrossRef]

31. Meier, M.; Patel, T.R.; Booy, E.P.; Marushchak, O.; Okun, N.; Deo, S.; Howard, R.; McEleney, K.; Harding, S.E.; Stetefeld, J.; et al. Binding of G-quadruplexes to the N-terminal recognition domain of the RNA helicase associated with AU-rich element (RHAU). J. Biol. Chem. 2013, 288, 35014-35027. [CrossRef] [PubMed]

32. Yaneva, M.Y.; Cheong, V.V.; Cheng, J.K.; Lim, K.W.; Phan, A.T. Stapling a G-quadruplex specific peptide. Biochem. Byophys. Res. Comm. 2020, 531, 62-66. [CrossRef] [PubMed]

33. Bhattacharyya, D.; Mirihana Arachchilage, G.; Basu, S. Metal Cations in G-Quadruplex Folding and Stability. Front. Chem. 2016, 4, 38. [CrossRef] [PubMed]

34. Behrendt, R.; White, P.; Offer, J. Advances in Fmoc solid-phase peptide synthesis. J. Pep. Sci. 2016, 22, 4-27. [CrossRef]

35. Del Villar-Guerra, R.; Trent, J.O.; Chaires, J.B. G-Quadruplex Secondary Structure Obtained from Circular Dichroism Spectroscopy. Angew. Chem. Int. Ed. Engl. 2018, 57, 7171-7175. [CrossRef] [PubMed]

36. Vorličková, M.; Kejnovská, I.; Bednářová, K.; Renčiuk, D.; Kypr, J. Circular dichroism spectroscopy of DNA: From duplexes to quadruplexes. Chirality 2012, 24, 691-698. [CrossRef]

37. Vorlíčková, M.; Kejnovská, I.; Sagi, J.; Renčiuk, D.; Bednářová, K.; Motlová, J.; Kypr, J. Circular dichroism and guanine quadruplexes. Methods (San Diego Calif.) 2012, 57, 64-75. [CrossRef]

38. Randazzo, A.; Spada, G.P.; Da Silva, M.W. Circular dichroism of quadruplex structures. Top. Curr. Chem. 2013, 330, 67-86.

39. Lim, K.W.; Ng, V.C.; Martín-Pintado, N.; Heddi, B.; Phan, A.T. Structure of the human telomere in Na+ solution: An antiparallel $(2+2)$ G-quadruplex scaffold reveals additional diversity. Nucleic Acids Res. 2013, 41, 10556-10562. [CrossRef]

40. Lim, K.W.; Amrane, S.; Bouaziz, S.; Xu, W.; Mu, Y.; Patel, D.J.; Luu, K.N.; Phan, A.T. Structure of the Human Telomere in K+ Solution: A Stable Basket-Type G-Quadruplex with Only Two G-Tetrad Layers. J. Am. Chem. Soc. 2009, 131, 4301-4309. [CrossRef]

41. Islam, B.; Stadlbauer, P.; Krepl, M.; Havrila, M.; Haider, S.; Sponer, J. Structural Dynamics of Lateral and Diagonal Loops of Human Telomeric G-Quadruplexes in Extended MD Simulations. J. Chem. Theory Comput. 2018, 14, 5011-5026. [CrossRef]

42. Villani, G. Quantum Mechanical Investigation of the G-Quadruplex Systems of Human Telomere. ACS Omega 2018, 3, 9934-9944. [CrossRef]

43. Zhang, X.; Xu, C.-X.; Di Felice, R.; Sponer, J.; Islam, B.; Stadlbauer, P.; Ding, Y.; Mao, L.; Mao, Z.-W.; Qin, P.Z. Conformations of Human Telomeric G-Quadruplex Studied Using a Nucleotide-Independent Nitroxide Label. Biochemistry 2016, 55, 360-372. [CrossRef] [PubMed]

44. Hill, A.V. The possible effects of the aggregation of the molecules of hæmoglobin on its dissociation curves. J. Physiol. 1910, 40, iv-vii.

45. Di Gaspero, M.; Ruzza, P.; Hussain, R.; Honisch, C.; Biondi, B.; Siligardi, G.; Marangon, M.; Curioni, A.; Vincenzi, S. The Secondary Structure of a Major Wine Protein is Modified upon Interaction with Polyphenols. Molecules 2020, 25, 1646. [CrossRef]

46. Honisch, C.; Hussain, R.; Siligardi, G.; Ruzza, P. Influence of small molecules on the photo-stability of water soluble porcine lens proteins. Chirality 2020, 32, 611-618. [CrossRef] [PubMed]

47. Hussain, R.; Longo, E.; Siligardi, G. UV-Denaturation Assay to Assess Protein Photostability and Ligand-Binding Interactions Using the High Photon Flux of Diamond B23 Beamline for SRCD. Molecules 2018, 23, 1906. [CrossRef]

48. Rachwal, P.A.; Fox, K.R. Quadruplex melting. Methods (San Diego Calif.) 2007, 43, 291-301. [CrossRef]

49. Ruzza, P.; Honisch, C.; Hussain, R.; Siligardi, G. Free Radicals and ROS Induce Protein Denaturation by UV Photostability Assay. Int. J. Mol. Sci. 2021, 22, 6512. [CrossRef] 